\title{
PENGARUH KUALITAS PELAYANAN DAN PROMOSI TERHADAP KEPUASAN PENGGUNA JASA PADA NADZIRA WEDDING ORGANIZER TULUNGAGUNG
}

\author{
Kristal Sauzhana Putri Sahroma', Moh. Anasrulloh² \\ Universitas Bhinneka PGRI Tulungagung \\ Sauzhana.crystal@gmail.com
}

\begin{abstract}
Abstrak
Nadzira Wedding Organizer merupakan salah satu perusahaan di bidang jasa yaitu wedding organizer yang menyediakan jasa untuk melayani acara pernikahan. Penelitian ini bertujuan untuk mengetahui pengaruh kualitas pelayanan dan promosi terhadap kepuasan pengguna jasa pada Nadzira Wedding Organizer Tulungagung. Metode pengumpulan data yang digunakan adalah metode kuisioner berupa angket. Metode analisis yang digunakan adalah uji validitas, uji reliabilitas, uji asumsi klasik, uji analisis regresi linier berganda uji t dan uji F. Penyusunannya menggunakan pendekatan kuantitatif. Hasil analisis menunjukkan bahwa terdapat pengaruh yang positif dan signifikan antara Kualitas Pelayanan dan Promosi terhadap Kepuasan Pengguna Jasa pada Nadzira Wedding Organizer Tulungagung dengan presentase 50,1\%. Dan nilai signifikansi antara Kualitas Pelayanan (X1) dan Promosi (X2) terhadap Kepuasan Pengguna Jasa $(Y)$ adalah sebesar $F_{\text {hitung }}>F_{\text {tabel }}(28,562>3,81)$ Berdasarkan hasil signifikansinya, $0,000<0,05$ maka dapat disimpulkan bahwa variabel Kualitas Pelayanan (X1) dan Promosi (X2) berpengaruh secara simultan terhadap variabel Kepuasan Pengguna Jasa $(Y)$.
\end{abstract}

Kata Kunci: Kualitas Pelayanan, Promosi, Kepuasan Pengguna Jasa

\section{PENDAHULUAN}

Saat ini, pada era globalisasi, dunia usaha sangat berkembang pesat, baik di sistem ekonomi, sosial budaya, dan teknologi. Salah satu bisnis yang berkembang mengikuti zaman adalah bisnis di bidang jasa wedding. Sebagai efeknya, banyak bermunculan usaha jasa wedding dan semakin banyaknya masyarakat yang menggunakan jasa wedding. Untuk menghadapi persaingan ini, pengusaha jasa wedding harus mampu memahami kebutuhan dan kualitas pelayanan yang memuaskan pengguna jasa. Dengan memahami apa yang diinginkan dan diharapkan oleh pengguna jasa dari kualitas pelayanan yang diberikan, maka akan didapat suatu nilai tambah tersendiri bagi pengusaha jasa wedding.

Kualitas pelayanan adalah seberapa jauh perbedaan antara harapan dan kenyataan para pelanggan atas layanan yang mereka terima, serta ketepatan penyampaiannya dalam mengimbangi harapan konsumen (Tjiptono, 2004) (Anasrulloh, 2017). Kualitas pelayanan adalah mutu dari pelayanan yang diberikan kepada pelanggan sebagai upaya pemenuhan kebutuhan dan keinginan tertentu. Setiap penyedia jasa memiliki keunikan masing-masing. Meskipun memiliki usaha dibidang sama tetapi semua memiliki cara masing-masing dalam memberikan kualitas pelayanan yang baik dan memuaskan para pengguna jasa.

Kepuasan pelanggan adalah tanggapan konsumen atas terpenuhi kebutuhannya (Amanah, 2017). Kepuasan adalah perasaan senang atau kecewa seseorang yang berasal dari perbandingan antara kesannya terhadap kinerja suatu produk dengan harapan harapannya (Wibisono \& , 2016). 
Hal itu berarti penilaian bahwa suatu bentuk keistimewaan dari suatu barang atau jasa, memberikan tingkat kenyamanan dibawah harapan atau pemenuhan kebutuhan melebihi harapan konsumen. (Amanah, 2017). Jika perusahaan gagal memenuhi ekspektasi, konsumen akan tidak puas. Jika perusahaan sesuai dengan ekspektasi, konsumen akan puas. Jika kinerja melebihi ekspektasi, konsumen akan sangat puas atau senang. (Gaol \& Hidayat, 2016).

Kualitas pelayanan dan kepuasaan pelanggan membentuk loyalitas.(Lusiana, 2015). Loyalitas pelanggan adalah ukuran semau apa pelanggan melakukan pembelian lagi. Semakin berkualitas pelayanan yang diberikan oleh perusahaan maka kepuasan yang dirasakan oleh pelanggan akan semakin tinggi. (Wibisono, 2016). Dengan terciptanya loyalitas pelanggan menciptakan keuntungan bagi perusahaan. Ketika klien telah merasa puas maka akan terjalin hubungan harmonis antara pengusaha dan pengguna jasa, menciptakan dasar yang baik untuk memesan kembali pelayanan jasa dan membentuk rekomendasi dari mulut ke mulut yang dapat menguntungkan bagi pengusaha. Pada jasa wedding, kepuasan pelanggan dapat diketahui dari pengalaman mereka sendiri saat menggunakan pelayanan suatu jasa wedding organizer dan testimoni dari orang lain.

Promosi zaman sekarang tidak hanya secara langsung, tetapi bisa menggunakan promosi secara online. Dengan kemajuan tehnologi saat ini semakin mudah bagi penyedia jasa dalam mempromosikan usahanya kepada klien. Promosi menurut (Lenzun et al., 2014) adalah serangkaian kegiatan untuk mengkomunikasikan, memberi pengetahuan dan meyakinkan orang tentang suatu produk agar ia mengakui kehebatan produk tersebut, juga mengikat pikiran dan perasaannya dalam suatu wujud loyalitas terhadap produk. Promosi merupakan kegiatan-kegiatan yang secara efektif dilakukan oleh perusahaan untuk mendorong konsumen membeli produk atau jasa yang ditawarkan (Gulla et al., 2015). Promosi ini terkait dengan berbagai kegiatan yang dilakukan oleh penyedia jasa untuk mencoba menjalin komunikasi baik dengan klien dan untuk mengetahui apakah produk yang dipromosikan akan sesuai dengan pelayanan yang diberikan yaitu dapat memberikan kepuasan kepada para pengguna jasa.

Berdasarkan latar belakang yang telah diuraikan, yang menjadi rumusan masalah pada penelitian ini adalah Apakah ada pengaruh Kualitas Pelayanan terhadap Kepuasan Pengguna Jasa Nadzira Wedding Organizer Tulungagung ? Apakah ada pengaruh Promosi terhadap Kepuasan Pengguna Jasa Nadzira Wedding Organizer Tulungagung ? Apakah ada pengaruh Kualitas Pelayanan dan Promosi secara simultan terhadap Kepuasan Pengguna Jasa Nadzira Wedding Organizer Tulungagung?.

Adapun manfaat dari penelitian ini adalah sebagai berikut : (1)Bagi perusahaan memberikan sumbangan pengetahuan untuk evaluasi dari kualitas pelayanan dan promosi pengguna jasa sehingga memberikan kepuasan pada pengguna jasa. (2)Bagi peneliti dan ilmu pengetahuan sebagai bukti pengembangan teori dengan keadaan praktis di lapangan.

\section{METODE PENELITIAN}

Penelitian ini dilakukan di Nadzira Wedding Organizer. Waktu penelitian dimulai pada bulan Maret 2021. Variabel bebas (X) terdiri dari Kualitas Pelayanan yang digambarkan dengan $X 1$ dan Promosi yang digambarkan dengan X2 Pelayanan Wedding Organizer merupakan suatu kegiatan utama sebuah penyedia jasa Wedding Organizer. Pada Nadzira Wedding Organizer Tulungagung, adapun indikator variabel kualitas pelayanan (X1) berdasarkan (Anasrulloh, 2017) meliputi: Tangibles atau bukti fisik, Reliability atau keandalan, Responsiveness atau ketanggapan, Assurance atau jaminan/kepastian, Empathy atau kepedulian. Dan indikator Promosi (X2) menurut (Nangoy et al., n.d.) meliputi, Promosi Penjualan, Periklanan, Tenaga Penjualan, Kehumasan/Publik Relation, Pemasaran Langsung

Variabel terikat yaitu Kepuasan Pengguna Jasa pada Nadzira Wedding Organizer yang digambarkan dengan symbol $(Y)$. Kepuasan Pengguna Jasa adalah sikap positif pengguna jasa 
terhadap pelayanan dari Nadzira Wedding Organizer karena adanya kesesuaian harapan dari pelayanan dibandingkan dengan kenyataan yang diterimanya. Adapun indikator Variabel Kepuasan (Y) menurut (Anasrulloh, 2017) meliputi, Kenyamanan yang dirasakan pelanggan pada saat pelayanan diberikan, Keyakinan pelanggan atas pelayanan yang diberikan, Minat untuk selalu membeli produk, Perasaan puas atas perhatian dan pelayanan yang diberikan oleh karyawan.

Untuk mendapatkan data-data yang sesuai dengan tujuan penelitian dalam penelitian ini menggunakan angket. Angket berikut diberikan kepada responden dan kemudian responden akan mengisinya sesuai dengan pendapat dan persepsi responden. Angket yang digunakan dalam penelitian ini menggunakan angket (kuisioner) tertutup. Angket tertutup adalah angket yang sudah disediakan jawabannya sehingga responden tinggal memilih (Arikunto, 2002). Dalam penelitian ini menggunakan bentuk skala Likert. (Sugiyono, 2014) menyatakan Skala Likert digunakan untuk mengukur sikap, pendapat, dan persepsi seseorang atau sekelompok orang. Dengan skala Likert, maka variabel akan dijabarkan menjadi indikator. Kemudian indikator tersebut dijadikan sebagai titik tolak untuk menyusun item-item instrumen yang dapat berupa pertanyaan atau pernyataan. Jawaban setiap item instrument yang menggunakan Skala Likert mempunyai gradasi dari sangat positif sampai sangat negative, yang dapat berupa kata-kata.

Tabel 1. Skor pengukuran Instrumen Angket

\begin{tabular}{lll}
\hline \multicolumn{2}{c}{ Alternatif Jawaban } & Skor \\
\hline Sangat Setuju & (SS) & 5 \\
\hline Setuju & (S) & 4 \\
\hline Ragu-Ragu & (RR) & 3 \\
\hline Tidak Setuju & (TS) & 2 \\
\hline Sangat Tidak Setuju (STS) & 1 \\
\hline
\end{tabular}

Keabsahan instrumen menggunakan uji validitas dan uji realibilitas, yaitu suatu instrumen adalah valid apabila $r$ hitung lebih besar dari r-tabel pada taraf kepercayaan tertentu, kemudian juga dengan melihat Correlations dengan membandingkan Sig. (2-tailed) dengan alpha 0,05 \%, apabila nilai signifikansi $>\square$ maka instrumen adalah Valid atau dapat dipercaya untuk digunakan sebagai alat pengumpul data karena instrumen tersebut sudah baik

Analisis Data pada dasarnya adalah menguji hipotesis. Pengujian hipotesis bertujuan untuk membuktikan hipotesis yang diajukan dalam penelitian, apakah diterima atau ditolak. Hipotesis merupakan jawaban sementara terhadap pertanyaan penelitian yang telah dirumuskan pada perumusan masalah. Dalam penelitian ini menggunakan Uji T, Uji F dan Uji Regresi Linier Berganda. Uji t digunakan untuk mengetahui pengaruh variabel bebas (independent) secara parsial terhadap variabel terikat (dependent). Dasar pengambilan keputusan dilakukan dengan kriteria angka probabilitas signifikan. Jika probabilitas (signifikansi) $>0,05$ maka Ho diterima dan Ha ditolak. Jika probabilitas (signifikansi) < 0,05 maka Ho ditolak dan Ha diterima. Menerima Ha berarti terdapat pengaruh yang signifikan antara variabel bebas $(X)$ dan variabel terikat $(Y)$ secara simultan. Uji $F$ untuk dengan membandingkan $F$ hitung dengan $F$ tabel dengan taraf signifikan $5 \%(0,05)$. Taraf signifikan adalah kesalahan dalam menerima atau menolak hipotesis. Dengan ketentuan adalah sebagai berikut:

1. $F$ hitung $<F$ tabel berarti hipotesis alternative $(\mathrm{Ha})$ ditolak. Jika

$F$ hitung $<F$ tabel maka Ho diterima dan Ha ditolak.

2. $F$ hitung $>F$ tabel berarti hipotesis alternative $(\mathrm{Ha})$ diterima. Jika

$\mathrm{F}$ hitung $>\mathrm{F}$ tabel maka Ho ditolak dan Ha diterima.

Uji Regeresi Linier Berganda adalah suatu alat analisis peramalan nilai pengaruh dua variabel bebas atau lebih terhadap variabel terikat untuk membuktuikan ada atau tidaknya hubungan fungsi atau hubungan kausal antara dua variabel bebas atau lebih dengan satu variabel terikat. 
Analisis ini digunakan untuk mengetahui pengaruh kualitas pelayanan (X1) dan Promosi (X2) terhadap kepuasan pengguna jasa Nadzira Wedding Organizer Tulungagung. Adapun analisis regresi tersebut dimasukkan dalam persamaan sebagai berikut : $Y=a+b 1 X 1+b 2 X 2$.

\section{PEMBAHASAN}

Berdasarkan tabel 2 dapat diketahui bahwa uji t untuk variabel X1 pada tabel Coefficient diperoleh thitung 5,026 dan tabel 2,002. Nilai signifikansi 0,000 $<0,05$ sehingga tolak $\mathrm{H}_{0}$ terima $\mathrm{H}_{\mathrm{a}}$. Maka secara parsial variabel kualitas pelayanan berpengaruh signifikan terhadap kepuasan pengguna jasa. (Diketahui bahwa uji t untuk variabel X2 pada tabel Coefficient diperoleh thitung 2,935 dan tabel 2,002 . Nilai signifikansi $0,005<0,05$ sehingga tolak $\mathrm{H}_{0}$ terima $\mathrm{H}_{\mathrm{a}}$. Maka secara parsial variabel promosi berpengaruh signifikan terhadap kepuasan pengguna jasa

Tabel 2. Hasil Uji T

\begin{tabular}{|c|c|c|c|c|c|c|c|c|}
\hline \multicolumn{9}{|c|}{ a. $\quad$ Coefficients $^{a}$} \\
\hline \multirow{2}{*}{\multicolumn{2}{|c|}{ Model }} & \multicolumn{2}{|c|}{ Unstandardized Coefficients } & \multirow{2}{*}{$\begin{array}{l}\text { Standardized Coefficients } \\
\text { Beta }\end{array}$} & \multirow[b]{2}{*}{$t$} & \multirow[b]{2}{*}{ Sig. } & \multicolumn{2}{|c|}{ Collinearity Statistics } \\
\hline & & $\mathrm{B}$ & Std. Error & & & & Tolerance & VIF \\
\hline \multirow[t]{3}{*}{1} & (Constant) & 32.233 & 5.715 & & 5.640 & .000 & & \\
\hline & kualitas pelayanan & .312 & .062 & .521 & 5.026 & .000 & .815 & 1.227 \\
\hline & promosi & .168 & .057 & .304 & 2.935 & .005 & .815 & 1.227 \\
\hline
\end{tabular}

(Sumber : data primer diolah dengan SPSS 26.0 2021)

Tabel 3. Hasil Uji T

\begin{tabular}{|l|l|l|l|l|l|l|}
\hline \multicolumn{7}{|c|}{ ANOVA $^{\mathrm{a}}$} \\
\hline \multicolumn{2}{|l|}{ Model } & Sum of Squares & df & Mean Square & F & Sig. \\
\hline \multirow{4}{*}{1} & Regression & 752.913 & 2 & 376.456 & 28.562 & $.000^{\mathrm{b}}$ \\
\cline { 2 - 7 } & Residual & 751.271 & 57 & 13.180 & & \\
\cline { 2 - 7 } & Total & 1504.183 & 59 & & & \\
\hline
\end{tabular}

a. Dependent Variable: kepuasan

b. Predictors: (Constant), promosi, kualitas pelayanan

(Sumber : data primer diolah dengan SPSS 26.0 2021)

Dari tabel anova Uji $F$, menghasilkan $F_{\text {hitung }}$ sebesar 28,562 , nilai signifikansi 0,000 dan $F_{\text {tabel }}$ sebesar 3,18 dengan nilai signifikansi 0,05. Karena nilai $F_{\text {hitung }}>F_{\text {tabel }}(28,562>3,81)$ maka menolak $\mathrm{H}_{0}$ menerima $\mathrm{H}_{\mathrm{a}}$. Sehingga dapat diketahui bahwa secara simultan ada pengaruh yang signifikan antara Variabel Kualitas Pelayanan (X1) ,Promosi (X2) terhadap Kepuasan Pengguna Jasa $(Y)$. Berdasarkan hasil signifikansinya, $0,000<0,05$ maka dapat disimpulkan bahwa variabel Kualitas Pelayanan (X1) dan Promosi (X2) berpengaruh secara simultan terhadap variabel Kepuasan Pengguna Jasa

Tabel 4. Koefisien Determinasi

\begin{tabular}{|l|l|l|l|l|}
\hline \multicolumn{4}{|c|}{ Model Summary $^{\mathrm{b}}$} \\
\hline Model & R & R Square & Adjusted R Square & Std. Error of the Estimate \\
\hline 1 & $.707^{\mathrm{a}}$ & .501 & .483 & 3.630
\end{tabular}

(Sumber : data primer diolah dengan SPSS 26.0 2021) 
Tabel 5. Hasil Uji Regresi

\begin{tabular}{|c|c|c|c|c|c|c|c|c|}
\hline \multicolumn{9}{|c|}{ Coefficients $^{a}$} \\
\hline \multirow{2}{*}{\multicolumn{2}{|c|}{ Model }} & \multicolumn{2}{|c|}{ Unstandardized Coefficients } & \multirow{2}{*}{\begin{tabular}{|l} 
Standardized Coefficients \\
Beta \\
\end{tabular}} & \multirow[b]{2}{*}{$\mathrm{t}$} & \multirow{3}{*}{ Sig. } & \multicolumn{2}{|c|}{ Collinearity Statistics } \\
\hline & & $\mathrm{B}$ & Std. Error & & & & Tolerance & VIF \\
\hline \multirow[t]{3}{*}{1} & (Constant) & 32.233 & 5.715 & & 5.640 & & & \\
\hline & kualitas pelayanan & 312 & .062 & .521 & 5.026 & .000 & .815 & 1.227 \\
\hline & promosi & .168 & .057 & .304 & 2.935 & .005 & .815 & 1.227 \\
\hline
\end{tabular}

(Sumber : data primer diolah dengan SPSS 26.0 2021)

\section{SIMPULAN}

Dari hasil tabel 4.17 diatas menunjukkan bahwa besarnya pengaruh secara simultan $\left(R_{2}\right)$ variabel bebas X1 (Kualitas Pelayanan) dan variabel bebas X2 (Promosi) terhadap variabel terikat (Kepuasan Pengguna jasa) adalah 50,1\% dan sisanya 49,9\% dipengaruhi oleh variabel-variabel lain selain variabel Kualitas Pelayanan dan Promosi.

Berdasarkan dari hasil penelitian maka dapat dijelaskan sebagai berikut,

1. Terdapat pengaruh kualitas pelayanan dan promosi terhadap kepuasan pengguna jasa pada Nadzira Wedding Organizer Tulungagung. Hasil tersebut menyebutkan bahwa semakin tinggi kualitas pelayanan dan promosi yang diberikan akan berpengaruh terhadap kepuasan pengguna jasa pada Nadzira Wedding rganizer Tulungagung.

2. Pengaruh kualitas pelayanan dan promosi terhadap kepuasan pengguna jasa pada Nadzira Wedding Organizer Tulungagung sebesar $50,1 \%$, sedangkan 49,9\% dipengaruhi oleh variabel lain selain variabel kualitas pelayanan dan promosi.

Hasil penelitian ini mendukung teori menurut (Tjiptono, 2004) dalam (Lusiana, 2015) Kualitas layanan dapat diartikan sebagai upaya pemenuhan kebutuhan dan keinginan konsumen serta ketepatan penyampaiannya dalam mengimbangi harapan konsumen. Hasil penelitian ini mendukung teori menurut Suryadi (2011:8) Promosi adalah serangkaian kegiatan untuk mengkomunikasikan, memberi pengetahuan dan meyakinkan orang tentang suatu produk agar ia mengakui kehebatan produk tersebut, juga mengikat pikiran dan perasaannya dalam suatu wujud loyalitas terhadap produk.(Lenzun et al., 2014).

\section{SARAN PENGEMBANGAN PENELITIAN LANJUT (FUTURE RISET)}

Melalui temuan ini, saran bagi Nadzira Wedding Organizer hendaknya meningkatkan Kualitas Pelayanan dan Promosi karena terbukti mempunyai hubungan dan pengaruh terhadap Kepuasan Pengguna Jasa. Dan bagi pengembangan penelitian selanjutnya adalah menggali lebih luas dan mendalam indikator kualitas pelayanan dan indikator kepuasan pelanggan.

\section{DAFTAR RUJUKAN}

Amanah, D. (2017). Pengaruh Harga Dan Kualitas Produk Terhadap Kepuasan Konsumen Pada Majestyk Bakery \& Cake Shop Cabang H.M. Yamin Medan. Jurnal Keuangan \& Bisnis, 2(1), 71-87. https://doi.org/10.17605/OSF.IO/HNGVJ

Anasrulloh, M. (2017). PENGARUH KUALITAS PELAYANAN TERHADAP KEPUASAN KONSUMEN PADA TOKO RITEL DH MART. Pengaruh Kualitas Pelayanan Terhadap Kepuasan Konsumen Pada Toko Ritel DH Mart, 9.

Arikunto, S. (2002). prosedur penelitian suatu pendekatan praktek. pt rineka cipta. 
Gaol, A. L., \& Hidayat, K. S. (2016). Pengaruh Kualitas Produk Terhadap Tingkat Kepuasan Konsumen Dan Loyalitas Konsumen. Jurnal Administrasi Bisnis (JAB)|Vol. 38 No. 1 September 2016, 38(1), 125-132.

Gulla, R., Oroh, S. G., \& Roring, F. (2015). Analisis Harga, Promosi, Dan Kualitas Pelayanan Terhadap Kepuasan Konsumen Pada Hotel Manado Grace Inn. Jurnal Riset Ekonomi, Manajemen, Bisnis Dan Akuntansi, 3(1), 1313-1322.

Handoko, B. (2017). Pengaruh Promosi, Harga Dan Kualitas Pelayanan Terhadap Kepuasan Konsumen Pada Titipan Kilat JNE Medan. Jurnal IImiah Manajemen Dan Bisnis, 18(1), 61-72. https://doi.org/10.30596/jimb.v18i1.1098

Lenzun, J. J., Massie, J. D. ., \& Adare, D. (2014). Pengaruh Kualitas Produk, Harga dan Promosi terhadap Kepuasan Pelanggan Kartu Prabayar Telkomsel. Jurnal EMBA, 2(3), 1237-1245. https://ejournal.unsrat.ac.id/index.php/emba/article/viewFile/5802/5335

Lusiana, V. (2015). PENGARUH KUALITAS LAYANAN DAN PELANGGAN SEBAGAI VARIABEL MEDIASI ( Studi pada Larissa Aesthetic Center Semarang ). 1-116.

Maharani Purnama, P. (2019). Pengaruh Kualitas Pelayanan Dan Harga Terhadap Kepuasan Konsumen Serta Dampaknya Pada Loyalitas Konsumen Wedding Organizer Di Kota Prabumulih. Jurnal IImu Manajemen, 7(2), 140. https://doi.org/10.32502/jimn.v7i2.1564

Nangoy, S., L. Mandey, S., \& Kawet, L. (n.d.). pengaruh promosi harga dan distribusi terhadap keputusan pembelian pakaian pada matahari. 1-30.

Setyo. (2017). Pengaruh Kualitas Produk Dan Harga Terhadap Kepuasan Konsumen "Best Autoworks." PERFORMA: Jurnal Manajemen Dan Start-Up Bisnis, 1, 755-764.

Sugiyono. (2014). metode penelitian kuantitatif , kualitatif, dan R \& D. ALFABETA, CV.

Wibisono, A., \& , S. (2016). Pengaruh Kualitas Jasa Pelayanan Terhadap Kepuasan Pelanggan JNE. PERFORMANCE " Jurnal Bisnis \& Akuntansi," 6(2), 32. https://doi.org/10.24929/feb.v6i2.268 